\title{
DEMOCRACIA ASAMBLEARIA Y LIDERAZGO. LA ACCIÓN POLÍTICA JORNALERA EN MARINALEDA
}

Félix TALEGO VÁZQUEZ*

\section{INTRODUCCIÓN ${ }^{1}$}

Marinaleda es una localidad sevillana de unos 2.500 habitantes, con una abrumadora mayoría de población jornalera (obreros agrícolas) respecto a otros sectores sociales, ubicada entre los extensos términos de Ecija, Osuna y Estepa, tierras, como sabemos, con una estructura de la propiedad agraria fuertemente concentrada. Marinaleda, desde los años de la llamada «transición política a la Democracia», se ha caracterizado por una intensidad particular en sus protestas sociales, que han estado fundamentalmente motivadas por un cuestionamiento radical de la estructura de la propiedad; por la impugnación de la concentración de la tierra en unos pocos latifundistas ${ }^{2}$.

* Departamento de Antropología Social. Universidad de Sevilla.

1. La investigación global en la que se inscribe este artículo ha sido subvencionada por la Dirección General de Bienes Culturales de La Consejería de Cultura de la Junta de Andalucía y parcialmente por la DGICYT. Se inscribe en el marco del Grupo de Investigación para el Estudio de las Identidades Socioculturales en Andalucía (GEISA), dirigido por el Dr. Isidoro Moreno. Los resultados generales de la misma han sido publicados (Talego, 1996a) después de su presentación como Tesis para la obtención del Doctorado.

2. En este texto vamos a procurar sobre todo hacer un análisis desde dentro del proceso político acaecido en Marinaleda, para lo que atenderemos a las repercusiones que para los marinaleños han tenido esas luchas y los principios que dicen defender. Conviene aclarar, por si ello no se desprendiera con la suficiente claridad del desarrollo del texto, que no vamos a llevar a cabo -como no lo hemos hecho en otros escritos- una crítica a la naturaleza ética, moral o ni siquiera política de las ideas que dicen y creen defender los afiliados y próximos al Sindicato de Marinaleda. No es el papel del antropólogo enjuiciar las ideas, sino comprobar los comportamientos, las causas que los motivan y las justificaciones que de ellos y para ellos dan los agentes sociales. No quisiera de ninguna manera que este texto fuera interpretado como una contribución al debate sobre las ideas de emancipación social, sobre la licitud de la igualdad, sobre la legitimidad o la ilegitimidad de la propiedad de la tierra, sobre el derecho de los hombres y mujeres a albergar esperanzas en un mundo mejor y a trabajar por conseguirlo. El texto trata sobre procedimientos políticos y es responsabilidad del lector valorar hasta qué punto esos procedimientos se adecuan y laboran por los fines en los que fundamentan su razón de ser. Al investigador no deben interesarle en cuanto que tal (sí como ciudadano, pero ese es otro ámbito) la verdad, la justicia o la falacia e iniquidad de los principios que dicen defender aquéllos a quienes estudia, sino cómo incide el terreno de los hechos sobre el de los principios y viceversa. He considerado inexcusable esta aclaración porque otros textos publicados sobre Marinaleda han dado lugar a confusiones de este tipo. Pero ya que he entrado en este ámbito de los principios deontológicos del papel del investigador, 
Hasta tal punto ganaron en perseverancia y contundencia las luchas y protestas de los jomaleros de Marinaleda, que este pequeño pueblo, situado entre las comarcas de la Sierra Sur y la Campiña sevillana, se convirtió pronto en un referente ineludible para todo el movimiento sindical del campo andaluz, y aun para todos los sectores políticos de izquierda que abogan por la participación ciudadana y por lo que ha dado en llamarse la democracia participativa o de base.

En todo el período, la mayoría de los jornaleros del pueblo han estado afiliados al SOC (Sindicato de Obreros del Campo), y, desde el año 1979, la CUT (Candidatura Unitaria de Trabajadores), salida del seno del Sindicato a nivel andaluz, mantiene la alcaldía del pueblo con un amplio margen de votos. Desde 1991 la CUT se ha integrado como un partido político más en el seno de la coalición Izquierda Unida Convocatoria por Andalucía. El Secretario Local del Sindicato y Alcalde ha sido desde el principio Juan Manuel Sánchez Gordillo, figura que sobresale del resto de los miembros del Sindicato y cuyo liderazgo en todo el proceso está fuera de toda duda, como lo demuestra, por ejemplo, el que desde el primer momento y hasta el presente haya sido él la única persona que ha hecho las funciones de contacto y enlace de tipo sindical, público y oficial con cualquier entidad exterior al Sindicato local y al pueblo (instituciones oficiales, otras organizaciones sindicales y políticas, prensa, etc.).

Nos proponemos en este artículo esclarecer las causas que han dado lugar a que el colectivo de jomaleros de este pueblo haya sostenido ese particular y extraordinario grado de conflictividad social; las motivaciones ideológicas y políticas que han determinado que los objetivos de las luchas derivaran casi desde el primer momento hacia la consecución de tierras ${ }^{3}$ Nos centraremos en los aspectos más sobresalientes de la realidad sociopolítica marinaleña, aquellos que han contribuido a hacer de este pueblo un referente ineludible de la izquierda y, particularmente, de las luchas agrarias desde los años de la transición política a la democracia,

diré sólo una cosa sobre ese terreno general de los principios de lo social: se olvida a menudo, a pesar de que el debate ha acompañado desde siempre la polémica intelectual que la invocación de cualquier idea no justifica, no debe justificar, cualquier procedimiento; una cosa son los fines y otra los medios para conseguirlos. Otros llegan más allá y afirman que no hay fines sino sólo medios, o que los fines deberían ser los medios. No descubriré nada nueno al afirmar que, a menudo, las mayores ignomimias han sido perpetradas invocando alguna idea definitiva de Justicia y Verdad, siendo cierto en más casos de lo que se querría reconocer que el ejecutor está imbuido profundamente del convencimiento de que el suyo es un acto por el bien de su grupo, su patria o hasta la humanidad entera.

3. Después de más de diez años de reivindicaciones y luchas casi ininterrumpidas, el Estado (Instituto Andaluz de Reforma y Desarrollo Agrario) les concedió en 1991 un total de 1159 Has. a diez cooperativas de jornaleros marinaleños, tierras que habían pertenecido al Duque del Infantado. Entorpecimientos burocráticos y legales han impedido durante mucho tiempo después que las tierras pasaran efectivamente en manos de estos jomaleros. No obstante, desde 1991, ellos han estado reuniéndose para preparar organizativa y técnicamente una sola cooperativa que lleve la explotación íntegra del conjunto de las tierras. A partir de 1994 han podido gestionar la siembra y cosecha de algunos productos, tras acuerdos con empresas públicas autorizadas por la Consejería de Agricultura para trabajar las tierras hasta que la cesión tenga lugar definitivamente. 
y no tanto para darles una respuesta definitiva, sino para ponerlas en interrogación, que es el primer paso que debe dar el investigador antes de pretender hallar respuestas definitivas. Del mismo modo, pretendemos que el lector, que seguramente no habrá sabido de Marinaleda y sus gentes más que por los medios de comunicación, tenga al final de la lectura una idea más cabal de la realidad del pueblo ${ }^{4}$.

Dos son los aspectos de la realidad local que considero que son claves para entender la configuración socio-política de Marinaleda en el período que va desde los años de la transición política hasta el presente: la configuración de la estructura política local y los efectos sociales, políticos y sobre la identidad de clase y local que han tenido las luchas y los trabajos voluntarios.

\section{CONFIGURACIÓN POLITÍCA LOCAL}

\section{Génesis del poder popular}

Antes de pasar a describir las más importantes instituciones políticas de la localidad, conviene decir algo sobre la forma cómo adquirió la preponderancia política el grupo encabezado por J. Manuel Sánchez Gordillo: pocos años después de la muerte de Franco, un grupo reducido de hombres, entre los que destacaba desde un primer momento el propio J. Manuel, se empeñó en implantar en Marinaleda la sección local del SOC, que en aquellos años se denominaba Comisiones de Jornaleros. Los promotores del proyecto no habían tenido hasta ese momento ninguna relevancia política en el pueblo, pero ello no fue obstáculo para que, en muy poco tiempo, lograran un número suficiente de afiliados entre la población jomalera como para dejar de ser algo testimonial. Bastaron algunos mítines protagonizados por líderes del Sindicato a nivel andaIuz (Francisco Casero) para que el Comité Local se ganara las simpatías de buena parte de los jornaleros del pueblo.

En tales actos políticos se dio a conocer como un brillante y apasionado orador el que desde estos primeros tiempos sería el cabeza visible del nuevo proyecto político y sindical, J. Manuel. Su cualidad de orador no debe pasar en absoluto desapercibida a la hora de entender el éxito rápido de este novedoso proyecto político, que no tenía antecedentes en Marinaleda y, por supuesto, ninguna conexión con organizaciones sindicales de la época de la II República.

Sin embargo, para explicar los pocos obstáculos que hallaron en el dominio del espacio político local hay que tener presente un factor básico y previo al de la más circunstancial y fortuita brillantez e inteligencia política de J. Manuel; es la situa-

4. La investigación ha sido dirigida por el Catedrático Isidoro Moreno. Este artículo constituye una versión reformada y ampliada de uno primero aparecido en el Anuario Etnológico de Andalucia, Consejería de Cultura y Medio Ambiente, 1992. 
ción de vacío político existente en el pueblo en estos años de incertidumbre y de rápidos cambios del posfranquismo: el grupo de personas que habían ocupado el Ayuntamiento en los últimos años del Régimen Dictatorial no tenían ningún resorte de poder económico significativo que les permitiera constituirse, o más bien, perpetuarse en los nuevos tiempos como una élite social y política seria. Eran en su mayor parte pequeños profesionales locales, de aquellos que preferían los gobernadores civiles simplemente porque dominaban los rudimentos de la escritura y porque no tenían un pasado «sospechoso» (es decir, que no se conociera de ellos o de sus familiares más cercanos que hubieran tenido ningún tipo de veleidad o proximidad al «bando republicano»). Los exiguos presupuestos municipales (en el año setenta y cinco no llegaban a los cinco millones de pesetas) y las pocas labores burocráticas no habían permitido la constitución de un grupo de poder sólido sobre una base meramente burocrática y de manejo de recursos públicos.

Y más allá de eso, tampoco fue posible reunir un grupo de personas dispuestas a llevar adelante el proyecto político de la UCD, que, en los pueblos, como sabemos, significó el compromiso entre la continuidad institucional y la necesaria renovación. Finalmente, fue presentada a las primeras elecciones locales una candidatura bajo las siglas de la UCD, pero fue algo de última hora y mal fraguado. En definitiva, no había base social que permitiese ese relevo político por la vertiente conservadora. Como ya queda dicho, el reducido número de pequeños comerciantes, los pocos profesionales, muchas veces forasteros, no eran suficientes para crear una alianza política con los pequeños propietarios agrícolas locales. Pudiera pensarse que los «pelentrines» (nombre con el que se conoce a los pequeños propietarios en la comarca) habrían hecho suyo el proyecto de la UCD, pues de hecho, desde el principio vieron con distancia, cuando no con hostilidad, el discurso político «jornalerista» y beligerante del Sindicato. Pero eso era harto improbable, pues hubiera sido improvisar demasiado, ya que los pequeños campesinos marinaleños también habían estado alejados del poder político local durante los cuarenta años de Franco.

En definitiva, para entender como llegó a configurarse el nuevo poder político, el «poder popular» es menester que retengamos algunas ideas centrales que se desprenden de lo dicho hasta aquí:

a) El discurso político del grupo de J. Manuel estaba dirigido en exclusividad al sector social jomalero; era un discurso sindicalista y de clase, centrado sobre motivos tales como la emigración (que afectó y afecta con particular intensidad a los jornaleros), el desempleo, la insuficiencia y el carácter vejatorio de los sistemas de ayuda al desempleo rural, etc.

b) La primera institución política a que dió vida el nuevo grupo fue la asociación sindical, y se dice que el Sindicato es el instrumento fundamental para la defensa de los intereses de los jornaleros. Esta máxima política dará lu- 
gar a algo sumamente importante desde que la CUT ganó las elecciones municipales en 1979: el Alcalde y los concejales de la CUT se autolegitiman en sus cargos tanto en cuanto se someten formalmente a esa institución fundamental de la clase que es el Sindicato, que se expresa a través de la Asamblea. Desde un análisis estrictamente formal -la formalidad sostenida por el que llaman poder popular-, el Ayuntamiento y su Alcalde no serían por tanto más que meros portavoces de la Asamblea. El estudio hermenéutico de este discurso, complementado con la observación de la praxis política llevada a cabo durante el trabajo de campo (año y medio de estancia en Marinaleda), descubre otras vertientes que no aparecen en el discurso formal, pero de esto trataremos más adelante.

c) El grupo de personas no identificadas con el Sindicato son en su mayoría el sector social de los pelentrines, que incluso lo ven con cierto temor por la semejanza que tiene ese discurso con el de la izquierda radical de los años de la II República (abolición de la propiedad privada, etc)

d) Este sector social de los pelentrines, por su propia debilidad en la configuración de la estructura social local, y por su inexperiencia política, fue incapaz de auspiciar y sostener un proyecto político propio, lo que da lugar a que la única palabra que se escuche en el foro político del pueblo durante el largo espacio de tiempo de ocho años (1979-1987) sea la del Sindicato; la gente del Sindicato creyó que en Marinaleda se había cerrado definitivamente la posibilidad de un proyecto político contrario a los intereses del Sindicato. De ahí que cuando se presentó a las elecciones locales de 1987 una candidatura bajo las siglas del PSOE, el hecho fue interpretado por unos y otros como una provocación y una impugnación del discurso del Sindicato, que se presentaba como la «voz del pueblo de Marinaleda».

\section{La Asamblea de Marinaleda: modelo formal y funcionamiento real}

El Sindicato se constituye en Marinaleda en el año setenta y ocho y presenta a las elecciones locales del setenta y nueve una candidatura de la CUT encabezada por J. Manuel. Con un alto índice de participación, algo que es característico de todas las consultas electorales en Marinaleda, obtiene nueve concejales frente a dos de la UCD, que, además, en su desconcierto (o desencanto), terminaron dando su apoyo a la candidatura a Alcalde de J.Manuel y se retiraron pronto a sus casas.

El Sindicato y su Asamblea funcionaron pues antes de tener a sus representantes en el Ayuntamiento, pero fue por poco tiempo y de una forma muy diferente a como lo sería luego: en esta fase anterior a las primeras elecciones locales, la Asamblea, que luego cobrará tanta relevancia, es un órgano intemo del Sindicato, que representa por tanto sólo a los afiliados y que repercute sólo en ellos; y aun- 
que los afiliados no eran pocos, no suponían ni mucho menos la mayoría de lo: jomaleros de Marinaleda. La Asamblea no cobró su verdadera relevancia y su sig nificado actual hasta que los sindicalistas no ocupan el poder municipal. El equipi de gobierno era representante del Sindicato y había prometido seguir sus directri ces; el Sindicato a su vez entiende que los poderes delegados han de ser los míni mos y que las decisiones se tomarán en Asamblea. Por tanto, ahora la Asamble no sólo dirime cuestiones de política interna o estrategia sindical, sino que tom: decisiones sobre cómo llevar a cabo la gestión municipal; decisiones que afecta1 a todo el pueblo, afiliados como no afiliados, simpatizantes o adversarios. La asambleas, ahora «del pueblo», siguen celebrándose en el local del Sindicato, perr no se le pone, formalmente, ningún impedimento a cualquier marinaleño que quier: asistir, hablar y votar. Más adelante veremos cómo sí hay ciertos impedimentos : que cualquier marinaleño o marinaleña entre sin más en la asamblea y, much menos, a que esté autorizado a hablar en ella, lo que nos conduce necesariament a dudar que tal foro político pueda ser definido correctamente como una asamblea

En la Asamblea (a partir de ahora entrecomillamos el término) se deciden desd، entonces cuestiones tan claves como la política de impuestos municipales, la polític: de viviendas, las prioridades culturales o deportivas, las obras públicas y, por supues to, las acciones reivindicativas que han de emprenderse para llevar a buen términc esas políticas y, en general, para conseguir la mejora del nivel de vida, la disminució o erradicación del paro jornalero, la consecución de tierras y otros objetivos má: ambiciosos que apuntan hacia la transformación de la sociedad global.

Siendo tan importante la Asamblea, es comprensible que vaya ganando adep tos, pero aun así resulta difícil de entender cómo se ha logrado un índice de par ticipación tan alto y tan duradero, y que exige tanto en el compromiso con la acciones de protesta que se llevan a cabo: el porcentaje de participación se hi mantenido desde entonces hasta hoy entre las 350 y las 800 personas, en un pue blo cuya población adulta no sobrepasa las 1500 personas, alcanzándose las ma yores cotas de participación, precisamente, en los momentos en que se llevan a cabr acciones de protesta; habiendo un porcentaje de asambleas durante todo el año nc inferior a dos semanales, y que se convocan diariamente en momentos de «lucha»

Para entender cómo ha sido y es posible esta especie de «movilización perma nente» de la mayoría de la población -aunque en los últimos años se detecta uni crisis en la capacidad de convocatoria-, hay que atender a dos hechos de impor tancia capital, aunque por sí solos no puedan explicarlo tampoco: 1) la distribu ción en la Asamblea de trabajos públicos, o, incluso, de trabajos del mercado co marcal; 2) significado y repercusiones de las luchas para la propia gente que la: lleva a cabo: las acciones colectivas de protesta no sólo deben ser entendidas com un medio de presión hacia el exterior que persigue el logro de objetivos concretos De cara al interior son también acciones rituales que redefinen a quienes partici pan en ellas y que tienen sus propias reglas. 
La perspectiva de las luchas como un nuevo conjunto ritual en la localidad tendrá su tratamiento en el siguiente apartado. Vamos a referirnos aquí al hecho de que todo lo que tuviera que ver con el Empleo Comunitario primero y con el PER después (Plan de Empleo Rural, o normativa de regulación de los trabajos públicos para desempleados que sustituyó en 1984 al Empleo Comunitario) se decidiese en la Asamblea. Qué duda cabe que esto forzó a ir a la Asamblea a todos los trabajadores del pueblo, necesitados como estaban y están de recurrir a esos sistema de ayuda al desempleo ${ }^{5}$. Y dicho así pareciera que los trabajadores se acercaron a la Asamblea con un simple interés pragmático economicista, para no quedarse sin «paro» (ayuda al desempleo), y quizá así fuera para algunos primeramente, pero pocos pudieron negar la evidencia de la sustancial mejoría que para ellos resultaba de esta nueva situación: se había pasado de un sistema en el que el poco dinero que llegaba por la vía del Empleo Comunitario servía para contratar «a los de siempre», a un sistema donde los propios trabajadores decidían qué tareas hacer, cómo hacerlas, quienes tendrían prioridad para llevarlas a cabo y, algo muy importante, quienes serían los «listeros $»^{6}$, pues estos también serían elegidos en la Asamblea por libre designación y rotativamente.

Se consiguió así que un sistema de desempleo que en la generalidad de los pueblos había servido para «amontonar a los jornaleros en las cunetas» y para que se aprovecharan algunos «listos» (los listeros), se convirtiera en Marinaleda en un sistema eficaz de trabajo colectivo con el que se acometieron importantes obras públicas, y todo porque el sistema fue sometido al arbitrio colectivo de los propios trabajadores. Y lo más importante, los trabajadores, participando y decidiendo sobre su ejecución, comenzaron a cambiar sus puntos de vista sobre el terreno de lo público y lo político, como patrimonio exclusivo de los «señoritos» y los «arrimaos». Ahora comprobaban que ellos podían decir también su palabra en tales asuntos. Atendiendo por el momento al discurso político formal de la dirección del Sindicato (J. Manuel), éste era el objetivo que se perseguía al «entregar» a la Asamblea la gestión de estos importantes recursos.

De cualquier forma, desde estos años del Empleo Comunitario, comenzó a hacerse real y constante la presencia masiva de trabajadores que puede observarse aun hoy en las «asambleas», un hábito tan extraño a las clases populares desde

5. En otro lugar (Talego 1996b) he llevado a cabo un análisis riguroso sobre los efectos sociales, políticos, ideológicos y sobre las economías domésticas jomaleras y de los pequeños propietarios que han tenido el Empleo Comunitario y el Subsidio de Desempleo y el PER.

6. Con este nombre se conocía a las personas que eran nombradas por el Ayuntamiento para controlar la asistencia a los trabajos del Empleo Comunitario. En la mayoría de los pueblos estos trabajadores se hicieron con sumas considerables de dinero mediante una fórmula que consistía en llegar a acuerdos individuales con los trabajadores que se prestaban a ello: el trabajador aceptaba pagarle la mitad de la peonada a condición de poder dejar de asistir al trabajo sin que el listero registrase su ausencia. Los jornaleros aprovechaban el día en otros trabajos. En mi estudio ya citado (1994) analizo los importantes efectos que tuvieron estas pequeñas pero generalizadas corruptelas sobre las políticas sindicales de las organizaciones jomaleras. 
hace tanto tiempo. El estudio de la Asamblea es esencial pues para entender todo el proceso político local, las propias características de la «lucha por la tierra» y la configuración final que adopte la Cooperativa de los Humosos.

La observación-participante me ha permitido entender el papel que J. Manuel desempeña en la Asamblea: la presencia de J. Manuel en la Asamblea, bien sea directa o delegada, es necesaria para que pueda llevarse a cabo; es el eje central de estas reuniones institucionalizadas. No se estaría en lo cierto afirmando que J. Manuel tiene una cierta preeminencia sobre los demás por su mayor entrega, capacidad oratoria o experiencia política; es más acertado decir que él es la expresión emblemática de la Asamblea, su símbolo nuclear. Esto que decimos tiene, por ejemplo, incluso su reflejo visual en el modo cómo se coloca la gente en la sala: sólo J. Manuel ocupa la presidencia y se sitúa frente al resto, al modo como se hace en una conferencia, en un mitin o en tantas ocasiones; sólo él decide qué temas deberán tratarse en cada Asamblea, de lo que la gente se entera allí mismo, y, aunque es cierto que cualquiera de los presentes puede plantear un tema fuera del orden del día, la intervención de ésta ha de ser necesariamente escueta y puntual (lo enseña la práctica de la asistencia continuada), para que no se alargue la sesión y para que no se reconduzca el orden que él ha planteado. Lo normal es que, cuando algunas personas consideran que tal o cual tema debería ser tratado, se lo propongan a él en privado, que decidirá finalmente si lo plantea en la Asamblea y cuándo. El tipo de relaciones que se establecen en las asambleas, en los turnos de palabras, en las discusiones, son de carácter radial, es decir, la palabra (y la mirada) se dirige siempre a J. Manuel, aunque indirectamente refiera a una opinión expresada antes por otro, que también la dirigió a J. Manuel.

Del mismo modo, o tal vez decir que por ello mismo, es posible afirmar que no hay en la Asamblea, ni en el Sindicato ni en el Ayuntamiento otro grupo de personas más o menos amplio o restringido que puedan tener una cierta ascendencia o un cierto liderazgo sobre la Asamblea o sobre subgrupos de la misma. El grado de aceptación que manifiesta la Asamblea hacia otras personas depende directamente de la sintonía ideológica y política que exista entre esas personas y J. Manuel. Las personas que a lo largo de estos años se han ganado el reconocimiento de la Asamblea, y de J. Manuel, han sido aquellas que han demostrado mayor entrega y sacrificio en los trabajos concretos que la Asamblea decidía que había que hacer; pero en todos los casos su relevancia política en el foro ha sido nula. Estos hombres «a quienes la Asamblea debe estar agradecida» no son más que ejecutores abnegados de decisiones, pero que no han desempeñado ningún papel particular cuando se gestaron. Más aun, se ha dado el caso de personas que terminaron manifestando un criterio distinto al de J. Manuel (algunos eran de los que se habían ganado su reconocimiento por su trabajo abnegado) y, a partir de entonces, por haber cuestionado la línea política diseñada por J. Manuel, sufrieron el rechazo de éste y, paso seguido, el de la Asamblea, y han terminado retirándose a sus casas. Con ellos 
llevan, además, el estigma recriminador del que abandona, traiciona o rehuye cobardemente el compromiso que exige la causa del poder popular.

Tampoco debe pensarse que J. Manuel haya adquirido un grado tal de dominio sobre los instrumentos políticos y sobre las conciencias que le permita dirigir a su capricho la orientación política que tome finalmente la Asamblea. Esto no le es posible al Alcalde (tampoco sabemos si su conciencia política le conduciría a forzar la situación a tal extremo de contravenir la voluntad expresa de las gentes del pueblo en aras de algún tipo de Bien Supremo que él pudiera concebir), y no le es posible, en cualquier caso, porque los instrumentos con que cuenta en su labor de liderazgo carismático son casi exclusivamente persuasivos, posibles a partir del manejo de ciertos recursos ideológicos y simbólicos. Ni desde el ámbito de la Asamblea, de la organización sindical o del Ayuntamiento ${ }^{7}$ es posible hacerse con unos resortes coactivos lo suficientemente sólidos como para impedir que cualquier persona decida finalmente dejar de asistir a las asambleas, que son el ámbito clave desde el que J. Manuel revalida su liderazgo carismático.

Ahora bien, precisamente en este sentido, es interesante observar que, en muy raras ocasiones en los doce años largos que dura el proceso político comandado por J. Manuel, han llegado a cuestionar los marinaleños en ninguna Asamblea o cualquiera de los otros órganos participativos dependientes de la misma, la palabra y el criterio del Alcalde, especialmente en las cuestiones que tienen calado político. La opción seguida por los que han disentido políticamente ha sido más bien retirarse de la Asamblea; todos han considerado que era inútil seguir en el «proceso» (vinculados a la Asamblea y al Sindicato) si no se compartían los criterios de J. Manuel y que era inútil pretender cuestionar su liderazgo. Porque su liderazgo y el criterio o la voz de la Asamblea son la misma cosa, elementos indisolublemente ligados en el modo como se ha construido el poder popular. Cuestionar uno de esos dos elementos significa, indefectiblemente, cuestionar el otro.

Pero, por otra parte, se hace necesario reconocer también que la solidez del liderazgo de J. Manuel se resiente con cada deserción, así como se fortalece con cada adhesión, porque muchas de las personas que se retiran o se suman a la Asamblea gozan de un respeto y consideración generalizado por parte del sector social jornalero y de los vecinos del pueblo. No en vano, hemos podido comprobar que

7. Téngase en cuenta la estrechez de las competencias políticas de los ayuntamientos en el ordenamiento político del Estado español, de lo que,precisamente, suele quejarse J. Manuel en sus alocuciones públicas. De todas formas, hay que tener en cuenta que en los últimos gobiernos del Régimen dictatorial y, sobre todo, los sucesivos gobiemos del Régimen democrático han puesto en manos de los alcaldes rurales andaluces la gestión y distribución local de los fondos destinados a regular el desempleo agrícola rural (el Empleo Comunitario y el PER), lo que les permite una dosis considerable de discreción, o de venalidad, en el reparto del trabajo que generan. Algo en absoluto despreciable, sobre todo en los municipios pequeños y empobrecidos de Andalucia. Ya lo hubieran querido para sí los alcaldes franquistas. 
J. Manuel dedica mucho tiempo y esfuerzo a impedir por todos los medios posi bles que nadie «abandone el proceso», y si entiende que alguien es ya iпrecupera ble para «la lucha», procura desacreditar a toda costa su opción, estigmatizándol y demonizándola, como ha hecho tantas veces, auspiciando así que los que conti núan en el proceso, particularmente los más entusiastas y convencidos, que sien ten el respaldo legitimador de la Asamblea, dirijan contra ellos los dardos hirien tes de la crítica social, que los desacredita, los margina, forzándolos incluso, com en algún caso, al ostracismo. Desde la óptica de quienes así actúan o lo apruebar. este es el coste que hay que pagar para mantener la cohesión interna, la fidelida a los principios por cuya razón de ser se legitima el proceso. Un ejemplo de lo abundantísimos: en un programa de la radio $\operatorname{local}^{8}$ donde se escandalizaba y rene gaba de aquellos que «después de haber visto tanta luz» (después de haber parti cipado plenamente en el proceso político que él comanda, el las luchas...) abando nan, prefieren las tinieblas, el conformismo, el consumismo del capitalismo, y le dedicaba una poesía en la que hablaba de la imposibilidad de «sacar manzanas di espinos».

A pesar de todo, y de la ausencia de mecanismos de coacción sólidos y efica ces, el proceso político se consolidó en Marinaleda muy pronto y ha continuad، teniendo vigencia hasta nuestros días, dando como resultado, entre otras cosas, ur comportamiento político de la mayoría de los marinaleños tremendamente parti cular, caracterizado por un grado bastante inusual de movilizaciones y protesta: contra los poderes establecidos fuera de Marinaleda: los latifundistas de la comar ca y el Estado fundamentalmente. No se trata tanto de enjuiciar y valorar en tér minos políticos esta dinámica. Se trata más bien de llegar a entender cómo ha sidc posible el afianzamiento de un proceso político como éste, en que el liderazgc carismático constituye un elemento sustancial. Sin duda que en ello ha influido li particular concepción política y la personalidad de J. Manuel, pero sin duda tam. bién, y esto es lo interesante, que ha sido posible gracias a las concepciones quє sobre la autoridad y el poder tienen esas personas que se sientan en las asamblea: frente a J. Manuel o que lo siguen a las ocupaciones, a los encierros, a las marchas, que son fundamentalmente jornaleros y que constituyen la mayoría del pueblo. Esas concepciones sobre el poder y la autoridad, sobre el «nosotros» y e

8. La radio local, «Radio Marinaleda», está controlada por el Sindicato. El programa a que me refierc es «Línea Directa», que se emite los sábados a la hora del almuerzo. Desde 1994 el programa se emite por la televisión local. En él, J. Manuel reflexiona sobre diversos temas locales y extralocales y recibe llamadas por teléfono que le interrogan sobre tales temas o cualquiera otros. Invariablemente, estas intervenciones adoptan la forma de la pregunta que se dirige a un maestro o experto, y no con ánimo de debatir o polemizas de igual a igual. Intentar rebatir la palabra autorizada de Juan Manuel sería tomado necesariamente por la audiencia como un intento de desacato a la autoridad de la Asamblea, pues ya hemos explicado que son la misma cosa. O visto del revés, la voz de Juan Manuel puede seguir siendo la de la Asamblea porque es la palabra incontestada, la última palabra. 
«ellos», sobre «los que saben» y «los que no saben», etc, forman parte de la concepción del mundo y, en definitiva, de la cultura del trabajo ${ }^{9}$ de la que son portadores.

\section{RECONSTRUCCIÓN DEL SISTEMA DE IDENTIFICACIÓN LOCAL: LAS LUCHAS Y LOS «TRABAJOS VOLUNTARIOS»}

En el verano de 1980, poco tiempo después de que la CUT ganara las elecciones locales, la mayoría de los jornaleros de Marinaleda deciden en asamblea iniciar una huelga de hambre para exigir la Reforma Agraria y el aumento de las partidas presupuestarias del Empleo Comunitario. Esta «gesta», que se prolongó por espacio de doce días, dio a conocer a este pequeño pueblo sevillano en toda Andalucía y el Estado español a través del reflejo que tuvieron los acontecimientos en la prensa. Después de esta primera y ejemplar protesta no ha pasado ningún año sin que los jornaleros de Marinaleda emprendieran acciones para llamar la atención sobre el creciente desempleo y la contradicción de ello con la extrema concentración de la tierra de la comarca en tan pocas manos. Para ello llevaron a cabo diversas ocupaciones simbólicas de latifundios, sobre todo, y a partir de 1985, lo hicieron en la finca «Los Humosos», propiedad del Duque del Infantado, queriendo indicar a los responsables de la Ley de Reforma Agraria que aquélla era la finca que querían trabajar los jornaleros en paro de Marinaleda. Todas estas acciones se han caracterizado por un amplio porcentaje de participación (entre trescientas y seiscientas cincuenta personas, hombres y mujeres, y de todas las edades) y por una perseverancia sin igual en la historia reciente de las movilizaciones sociales andaluzas.

Aparte de estas luchas, los trabajos voluntarios han sido el otro gran motivo de acción colectiva de los jornaleros que pertenecen a la Asamblea: los afamados «Domingos Rojos» (trabajos voluntarios realizados los domingos), o las horas de trabajo voluntario en el Empleo Comunitario o el PER, o los trabajos voluntarios en el bar del Sindicato y en la Feria, etc. En las fiestas es normal cada año que trabajen unas trescientas personas voluntarias para llevar las consumiciones de la

9. Utilizo el concepto de «cultura del trabajo» elaborado por I. Moreno: «...Al igual que ocurre con otros conceptos claves, como modo de producción o campesinos, entiendo existen dos acepciones, una restringida y otra amplia. ...En la primera, puede entenderse por cultura del trabajo el conjunto de comportamientos, normas, valores, etc. que poseen los integrantes de un grupo social sobre el sector de su realidad que tiene que ver directamente con el proceso productivo; con lo que suele denominarse ámbito laboral. En la segunda acepción, que subsume a la anterior y es la que nosotros consideramos más útil, los contenidos de la cultura del trabajo desbordan dicho ámbito y se refieren a todo el conjunto de la vida social y al sistema de pensamiento global de los individuos. La orientación cognitiva de un sector social, su ethos, la visión del mundo de sus componentes, entraría dentro del concepto», I. Moreno, 1990 pp. 73-93. Puede consultarse también para un análisis más detenido del concepto, I. Moreno, 1991, pp. 601-636. 
caseta y todos los trabajos de organización. Esto se hace así todos los años desd 1979. El dinero que se consigue va a parar a las arcas del Sindicato, de donde sale después los fondos para garantizar la resistencia y la perseverancia en las lucha:

$\mathrm{Si}$ atendemos sólo a la vertiente formal de lo que es el discurso político de . Manuel, a las explicaciones de los protagonistas y al mensaje inmediato del ler guaje simbólico de sus acciones, tenemos que las luchas han sido el instrument necesario para llamar la atención sobre la situación de desempleo y la falta de pers pectivas de la juventud, o más rotundamente, para exigir que la tierra debe ser par quien la trabaja «...la tierra no es de nadie porque nadie la ha hecho. Es además 1 llave de la alimentación humana, y, por ese motivo, ha de ser de la comunidad qu la habita y la trabaja» ${ }^{10}$. La contundencia y la perseverancia deben ser entendida en este sentido como una manifestación simbólica más de ese discurso explícit que intentamos traducir aquí, y significaría que los jornaleros en paro que da cuerpo a la Asamblea sienten vivamente, como algo insoportable, la situación d opresión e injusticia en que viven: «Si las peticiones no se atienden o son burlada una vez más por la Junta de Andalucía, estamos dispuestos a llegar hasta las últ. mas consecuencias y con cuantos medios dispongamos y hasta la vida, por cons $\epsilon$ guir nuestro derecho constitucional a un puesto de trabajo...» ${ }^{11}$.

Los trabajos voluntarios serían desde esta óptica «una escuela para la eduč ción en una sociedad más justa y solidaria» (programa «Línea Directa»10-91), de paso, la afirmación, también a nivel simbólico, para los de fuera, e incluso, más importante, para los de dentro, de que esa sociedad está más cercana e Marinaleda.

Sin embargo, como ocurre siempre, la realidad es más compleja, más diversa incluso distinta de los que se nos muestra en los discursos formales o en una lec tura simple y lineal de las acciones simbólicas. Y, en todo caso, si la realidad en $\mathrm{s}$ multiplicidad y contradicciones está reflejada en el lenguaje simbólico y en el r tual, no puede ser descubierta si no es con una lectura minuciosa y concienzudi que pueda, por así decirlo, leer entre líneas. Pues bien, la inmersión en la vida loci nos ha permitido hacer una lectura crítica del discurso que se expresa en el ler guaje hablado o escrito y en las acciones simbólicas. Esta lectura nos ha llevado poner en duda que el «hambre de tierras» o la percepción de la propia situació como de una «injusticia intolerable» se presente en las conciencias de la gente ti y como se presenta en el discurso, discurso que es sostenido, paradójicamente, pc la mayoría de esas gentes.

10. Fragmento de la moción presentada por el Alcalde a la sesión plenaria del Ayuntamiento del día 2 12-87 sobre la necesidad de cambiar la normativa del Subsidio de Desempleo; Actas Capitulares, libro 2 p. 111 y sig.

11. Fragmento de la moción presentada por el Alcalde a la sesión plenaria del Ayuntamiento del día 2 5-90 sobre apoyo del Ayuntamiento a la petición de las tierras del Humoso, Actas Capitulares, libro 26, 151 y sig. 
Sin embargo, tampoco sería correcto afirmar que el discurso simbólico subvierte o niega la realidad: ningún grupo de poder local que requiera de la movilización frecuente de la gente podría sostenerse ni sostener su discurso frente a las inclinaciones e intereses de la mayoría del pueblo durante tanto tiempo. Pero esto no impide poner en duda la correspondencia total entre esos dos ámbitos de la realidad social. Hemos comprobado que la generalidad de quienes hacen posible el poder popular con su asistencia a las asambleas, a las luchas y los trabajos voluntarios entienden que el discurso recoge y formula convenientemente, de un modo conclusivo y sistemático, lo que debería ser, es decir, el orden al que deberían plegarse las cosas de este mundo, del mundo real del aquí y el ahora. Por tanto, ese discurso se ha constituido a sus ojos como un referente ideológico sustentador de un deber ser, de un orden normativo, que es el fundamento legitimador de todo el entramado del poder popular y de sus acciones, puesto que se cree a aquél y a éstas los intrumentos adecuados para conformar o reconducir el aquí y el ahora hacia el desideratum, hacia el deber ser o metanivel (Ibáñez, 1989, 1992) que encierra el discurso. Se trata de un fenómeno típico de ideologización y sacralización de principios (Moreno, 1993), por el que lo más particular y concreto del aquí y el ahora es interpretado en función de su mayor o menor adecuación al más allá, que no tiene por qué ser sobrenatural, pero que es de signo profético, puesto que se lo considera realizado/realizable en un más allá o en un tiempo venidero (Elíade, Adomo, Cohn, Laplantine).

Pero más aun, porque el mecanismo de la redistribución político-ideológica ${ }^{12}$ -mecanismo que es está en la base de la concesión-denegación de los bienes de salvación en las religiones, pero común a las diversas formas de ideologías laicasopera en Marinaleda, como no podía ser de otra manera, toda vez que es operativo un orden ideal normativo; mucha de la gente ganada para el proceso cree-aunque con un grado de convicción variable- que algunos de los recursos o servicios que han recibido en estos años (viviendas, infraestructuras, trabajos, aumentos en la cuantía del desempleo, etc), son debidos al poder popular y a las luchas, por lo que se sienten en deuda con ese entramado y con aquel que encarna del modo más acabado los principios que lo fundamentan, J. Manuel (que dice de sí mismo que es «el primero en los sacrificios y el último en los beneficios»). Ciertamente, muchos consideran que es un testimonio, aquél que con su ejecutoria intachable nos anuncia ya lo que será el mañana.

Esto mismo nos ayuda a comprender mejor que J. Manuel haya logrado en el marco de la localidad capitalizar eso que Bourdieu (1988) ha llamado «la alquimia de la representación», es decir, el mecanismo mediante el cual una persona, un grupo, normalmente reducido, logra decir y actuar como si fuera la colectividad a la que dice representar. La cuestión es saber cómo ha sido posible el proceso

12. La redistribución, como la reciprocidad, es un «hecho social total», no sólo económico (Mauss, 1971). 
hasta que se alcanza ese estadio en que ya es posible la representación, en que po boca de J. Manuel ya pueden hablar todos los del sindicato, o, lo que es lo mismo en que J. Manuel ha suplantado la palabra de todos los del Sindicato. Para com prender este proceso y su éxito final es menester analizar los contenidos del dis curso o conjunto de proposiciones básicamente coherentes que sostiene el repre sentante, es decir, J. Manue ${ }^{13}$ y hasta qué punto tales proposiciones conectan o st corresponden con los saberes y las ideas recurrentes de los jornaleros a los qui representa, es decir, con su cultura del trabajo, aspecto este que nos es imposiblt desarrollar aquí y al que nos hemos aproximado en otro lugar (Talego, 1996b)

Quizá sea arriesgado afirmar que el discurso político surgido del proceso de crea ción y consolidación de la Asamblea, que tiene su símbolo más emblemático, su en carnación en la persona del propio Alcalde, no sea, al fin y al cabo, sino el discursc de un nuevo aparato de poder (todo lo endeble que se quiera, pero aparato en defini tiva) con sus mecanismos de control y de castigo de la disidencia, que se interpon entre las conciencias de la gente, en este caso no tanto para acallar u ocultar el des contento, sino precisamente para ampliarlo, incluso deformándolo. Los discurso: simbólicos de algunos aparatos de poder se legitiman como discurso de la realidar en tanto que garantizan la paz social, la desmovilización de los ciudadanos. El dis curso del nuevo poder surgido en Marinaleda, sin embargo, parece autolegitimarsı tanto en cuanto es capaz de mantener la movilización y la protesta de la gente frent al exterior, más concretamente frente a otras instancias de poder superior.

Queda por decir algo de los rituales y otras acciones simbólicas que ha genera do el nuevo poder. Es a través de la ejecución de estos rituales como se procede : definir y categorizar a los individuos en función de una jerarquía específica y ca racterística; a través de las luchas y los trabajos voluntarios se define quienes está en la Asamblea y profesan el nuevo discurso frente a los que no lo están; quiene: no participan en estos rituales no pueden ir a la Asamblea, o más claramente aun quienes están en la Asamblea (quienes asumen el nuevo poder) deben mostrarlo : través de su participación en esos rituales. Esto no está escrito en ningún sitio; sı aprende con la interacción social continuada.

13. Lo que sería tremendamente inadecuado, aunque complaciente para muchas conciencias de las qu se entienden a sí mismo «cultas», es considerar que el mecanismo de la representación, esa «alquimia» e posible en entre los jomaleros de Marinaleda porque ellos son «incultos», «ignorantes» y que nada de es. ocurriría si tuvieran más conocimientos de los que se adquieran en las escuelas los institutos y la universidades. Pensar la cuestión en estos términos demuestra más bien una ceguera supina, pues cada un de nosotros se encuentra representado en múltiples ámbitos del entramado social, desde la Jefatura del Estad para bajo, con un grado de independencia considerable a la identificación que en cada caso se pueda tene con la entidad o la persona que en cada caso nos representa. También en Marinaleda encontré mucha gent que disentía en bastante de las palabras y las acciones de J. Manuel, lo que no impedía, ni ha impedid hasta el momento, que estuvieran representadas por él. Los mecanismos de la delegación consisten, entr otras cosas, en asegurar su propia necesidad, su inevitabilidad, por medio de múltiples recursos disuasore de la explicitación de la disidencia, de la abierta manifestación del no reconocimiento del delegado. 
Es posible por tanto afirmar que en Marinaleda ha ocurrido una reformulación de la identidad local; hay una nueva forma de entender el «ellos» y el «nosotros». Esto explica lo ya apuntado en el apartado anterior de que las luchas y los trabajos voluntarios fueron un empujón definitivo para la consolidación de la Asamblea como nuevo órgano político y agregado de individuos que se autoperciben como distintos. Quienes han participado en estos actos perciben, y así es entendido por los demás, que han dado un paso hacia delante y se han desmarcado de las viejas formas de jerarquía, de sus rituales y de sus representantes.

Pero obsérvese que hablamos de sistema de identificación local y no de una mera identidad del sector social jornalero de Marinaleda (ya dijimos al principio que Marinaleda cuenta con un número significativo de familias de «pelentrines», que se han mantenido al margen cuando no enfrentados a este «nuevo poder»), pues es el caso que este nuevo discurso simbólico se presenta como la concreción de la identidad de todos los marinaleños: la Asamblea quiere representar a Marinaleda, y allí se decide todo lo que tiene que ver con Marinaleda. El discurso de autolegitimación lo dice muy claramente: si la Asamblea es pública y a nadie se le niega la voz, no hay razón para que exista nada en Marinaleda en política o jerarquías que no puedan tener cabida en ella. A la vista de esto, no debe sorprender que en el año 1983 se produjeran los conflictos en las celebraciones de la Semana Santa local, que dieron lugar a que el sistema ritual de hermandades, que servía para representar la jerarquía tradicional en el pueblo y el «viejo poder», fuese contemplado desde la Asamblea como una provocación, una impugnación de la misma. Desde ese año, las celebraciones de Semana Santa procuran ser ignorados, para lo que se realizan actos paralelos en el local de la Asamblea. Por eso, asistir a los rituales de la Semana santa en Marinaleda, o a la Romería, significa cuestionar el poder de la Asamblea (Robles, 1987; Talego, 1996a).

De ahí también que la continuación de estas celebraciones de Semana Santa y de la Romería se hayan convertido en el objetivo político fundamental de «La Contra», (que es como se conoce en los ámbitos del Sindicato al grupo de personas manifiestamente opuestas al proyecto político comandado por J. Manuel), como conjunto ceremonial que por medio de su celebración demuestra que el monopolio de la palabra de J. Manuel, o lo que es lo mismo, del Sindicato y la Asamblea, no es absoluta en Marinaleda, sino que hay un grupo socio-político que se resiste a ser absorbido por el Sindicato y que simbólicamente lucha cada año por su derecho a manifestarse, a salir a la luz, como temiendo que si algún año dejan de llevar a cabo sus celebraciones ya habrán dejado de existir políticamente y que se habrá hecho realidad lo que constituye una de las máximas del discurso: que Marinaleda es su Sindicato, o que el Sindicato y su portavoz son la única voz en Marinaleda. 


\section{BIBLIOGRAFÍA}

ADORNO, T. Y HORKHEIMER: La dialéctica del iluminismo, Madrid, Taurus, 1976 BOURDIEU, P., 1988: Cosas dichas, Buenos Aires, Ed. Gedisa.

COHN, N.: El cosmos, el caos y el mundo venidero, Barcelona, Crítica, 1995.

ELÍADE, M.: Historia de las creencias y de las ideas religiosas, Barcelona, Herder, 1996. IBÁÑEZ, T.: El conocimiento de la realidad social, Barcelona, Ed. Sendal. 1989.

— Y después de la muerte de Dios... ¿qué?. Variaciones ingenuas a partir de Heidegger, la postmodernidad y el cinismo, en Archipiélago. Cuadernos de crítica de la cultura, $\mathrm{n}^{\circ} 5$, Barcelona, Ed. Archipiélago, 1992.

LAPLANTINE, F.: Las voces de la imaginación colectiva, Barcelona; Granica Editor, 1977. MAUSS, M., Sociología y Antropología, Madrid, Tecnos, 1971.

MORENO, I., 1984: «Reforma agraria e identidad andaluza, implicaciones simbólicas del prohlema de la tierra en Andalucía» en Nación Andaluza, $\mathrm{n}^{\circ}$ 2-3.

— 1993, «Cultura del trabajo e ideología: el movimiento campesino anarquista andaluz», en Andalucía: Identidad y Cultura, Málaga, Ed. Librería Agora, pp 53-67.

1991, «Identidades y rituales», Antropología de los pueblos de España, Prat, J., Martínez, U., Contreras, J, y Moreno, I. (Coords), Madrid, pp. 601-636.

- 1993: Secularización o pluraliad de sacralidades en el mundo contemporáneo, en El mito y lo sagrado en la literatura y el pensamiento contemporáneos, Sevilla, (e.p.).

ROBLES, M., 1987: Contrapuntos simbólicos de la acción social; implicaciones simbólicas del problema de la tierra en Andalucía. Marinaleda (Sevilla)», en Revista de Estudios Andaluces, $\mathbf{n}^{\circ} 9$ (1987), pp. 87-110.

TALEGO, F., 1993: «Culturas del trabajo, estructura política e identidad local: el caso de Marinaleda», Sistemas de identidades y su expresión en las sociedades locales, Emma Martín Díaz (Coord.), Actas del VI Congreso de Antropología, Asociación Canaria de Antropología, Tenerife, 1993, pp. 197-211.

- "Culturas del trabajo, conflicto político y discursos simbólicos en Marinaleda", Anuario Etnológico de Andalucía 1991, Junta de Andalucía, Consejería de Cultura y Medio Ambiente, Sevilla, 1993b, pp. 195-204.

- «Transformación de una ideología revolucionaria en un discurso de poder: el caso de Marinaleda», Anuario Etnológico de Andalucía 1992-1993, Junta de Andalucía, Consejería de Cultura y Medio Ambiente, Sevilla, 1995, pp. 131-139.

- « Cultura del trabajo jornalera, discurso político y liderazgo: el caso del poder popular de Marinaleda» Revista de Antropología Social, n 4, Madrid, Servicio de Publicaciones de la Universidad Complutense, 1995b pp. 131-151.

- Cultura jornalera, poder popular y liderazgo mesiánico. Antropología política de Marinaleda, Sevilla, Universidad de Sevilla y Fundación Blas Infante, 1996a.

- Entre el trabajo y los subsidios de desempleo: los jornaleros de Lebrija, Sevilla, Ed. Hermandad de los Santos de Lebrija, 1996 b.

__ «as "necesidades» de los jornaleros: el consumo y la interacción social. El caso de Lebrija», en Revista de Estudios Andaluces, n² 21, Sevilla, Universidad de Sevilla, 1997. 